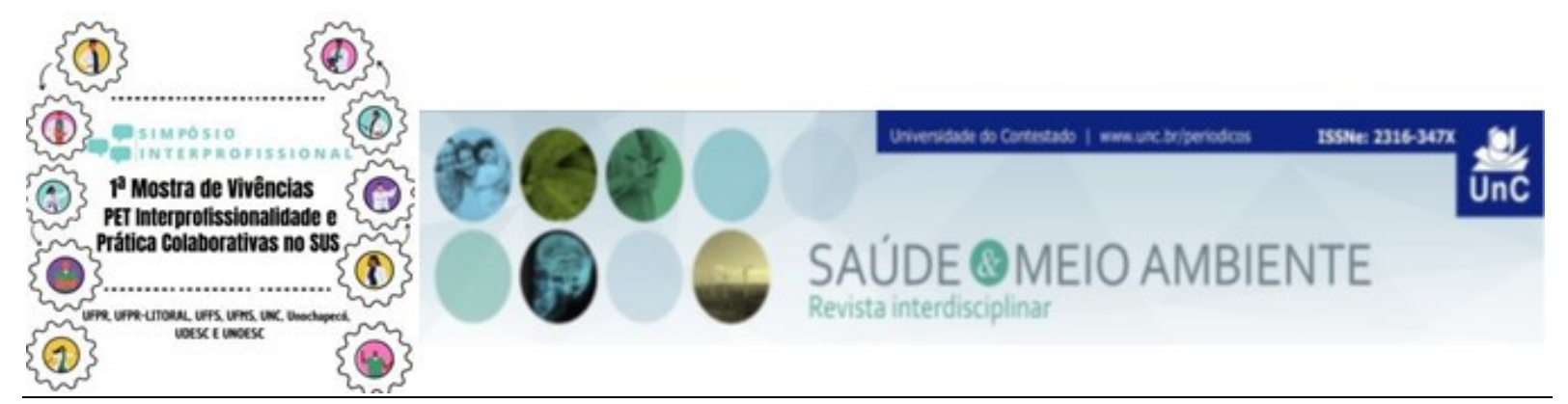

\title{
TELEMONITORAMENTO PARA O GERENCIAMENTO DOS CUIDADOS A SAÚDE EM HIPERTENSOS E DIABÉTICOS EM TEMPOS DA COVID-19, NO MUNICÍPIO DE PIRAQUARA-PR ${ }^{1}$
}

\author{
Julia Schlichting Azevedo ${ }^{2}$ \\ Andressa Marcele Maia Guimarães ${ }^{3}$ \\ Emanueli Cristini Souza da Costa ${ }^{4}$ \\ Alice Costa Silva ${ }^{5}$ \\ Naiana Boaventura dos Santos ${ }^{6}$ \\ Rosali Alves Pereira ${ }^{7}$ \\ Lucélia Justino Borges ${ }^{8}$ \\ Marilene da Cruz Magalhães Buffon ${ }^{9}$
}

\begin{abstract}
RESUMO
Introdução: Com o início da pandemia da COVID-19, os atendimentos nas Unidades Básicas de Saúde (UBS) do município de Piraquara sofreram adequações para priorizar o atendimento de casos suspeitos ou confirmados da COVID-19, sendo que os atendimentos eletivos foram suspensos, adotando medidas preventivas como o distanciamento social, para diminuição da transmissão comunitária ${ }^{1}$. A Secretaria Municipal de Saúde (SMS) em parceria a com UFPR, por meio do grupo tutorial Promoção da Saúde do Programa de Educação pelo Trabalho-Saúde Interprofissionalidade, desenvolveram uma estratégia de telemonitoramento para atender a demanda contínua de assistência aos pacientes com doenças crônicas, desassistidos pelo atendimento presencial nas UBS. Objetivo: Relatar a experiência
\end{abstract}

\footnotetext{
${ }^{1}$ Fonte de financiamento: MINISTÉRIO DA SAÚDE. Relação com projeto: acadêmicos e preceptores bolsistas do programa PET-Saúde Interprofissionalidade/ Ministério da Saúde, sob a orientação dos professores tutores Dr. Edison Luiz Almeida Tizzot, Dr ${ }^{\mathrm{a}}$ Lucélia Justino Borges, Dr ${ }^{\mathrm{a}}$ Marilene da Cruz Magalhães Buffon.

${ }^{2}$ Acadêmica integrante do PET-Saúde, cursando Odontologia na Universidade Federal do Paraná. Paraná. Brasil. E-mail: juliaschlichting@hotmail.com

${ }^{3}$ Acadêmica integrante do PET-Saúde, cursando Educação Física na Universidade Federal do Paraná. Paraná. Brasil. E-mail: andressamarcelle@gmail.com

${ }^{4}$ Acadêmica integrante do PET-Saúde, cursando Medicina na Universidade Federal do Paraná.

Paraná. Brasil. E-mail: emanueli.costa@ufpr.br

${ }^{5}$ Enfermeira atuante na Secretaria Municipal de Saúde de Piraquara. Paraná. Brasil. E-mail: aliceecosta.ac@gmail.com

${ }^{6}$ Preceptora do PET-Saúde, Profissional de Educação Física atuante no NASF-AB em Unidades Básicas de Saúde em Piraquara. Paraná. Brasil. E-mail: naiboaventura@gmail.com

${ }^{7}$ Preceptora do PET-Saúde, Cirurgiã-dentista atuante em Unidade Básica de Saúde em Piraquara.

Paraná. Brasil. E-mail: rosali.pereira@piraquara.pr.gov.br

${ }^{8}$ Tutora do PET-Saúde, Professora do Departamento de Educação Física da Universidade Federal do Paraná. Paraná. Brasil. E-mail: lucelia.borges@ufpr.br

9Tutora do PET-Saúde, Professora do Departamento de Saúde Coletiva da Universidade Federal do Paraná. Paraná. Brasil. E-mail: marilenebuffon@gmail.com
} 
do telemonitoramento de pacientes hipertensos e diabéticos do município de Piraquara-PR, visando garantir o acesso ao cuidado em saúde, em tempos de pandemia. Metodologia: O telemonitoramento realizado pelos acadêmicos iniciou em junho, após planejamento junto a SMS. Foram identificados os usuários a serem monitorados: 1.206 hipertensos e 506 diabéticos, cadastrados em 10 UBS. Os dados coletados foram inseridos em planilhas compartilhadas de forma online. $\mathrm{O}$ tempo médio das ligações foi de 15 minutos, realizadas em três períodos: manhã, tarde e noite. Resultados: Foram concretizadas 230 ligações para hipertensos (64\% eram mulheres) com idade de 35 a 91 anos e 84 ligações para o grupo dos diabéticos $(58,3 \%$ mulheres) com idade variando de 3 a 80 anos. Quanto à abordagem, foram repassadas orientações a respeito do controle das respectivas doenças e para manutenção do tratamento, além de orientações sobre alimentação saudável, atividade física e cuidados no combate a COVID-19. Além disso, a ação oportunizou momento de escuta ativa, na qual os usuários expressaram suas necessidades e angústias, devido ao isolamento social. As urgências de saúde citadas foram sinalizadas para a SMS, e encaminhadas para as UBS de origem do usuário. A limitação do processo foi a quantidade de números inexistentes e ligações não atendidas. Considerações Finais: $O$ telemonitoramento possibilitou responder às necessidades de saúde desses grupos, reduzindo a exposição destes ao contágio pelo coronavírus, visando o controle das doenças e evitando complicações quando associadas a evasão ao tratamento, além de oportunizar aos acadêmicos práticas interprofissionais com os trabalhadores da rede de saúde do município.

Palavras-chave: Promoção da Saúde. Educação Interprofissional. Saúde Coletiva. Telemonitoramento. Pandemia.

\section{REFERÊNCIAS}

1. BRASIL. Agência Nacional de Vigilância Sanitária. Nota Técnica GVIMS/GGTES/ANVISA n ${ }^{\circ} 04$ de 30 de janeiro de 2020 - revisada em 08/05/2020. Orientações para serviços de saúde: medidas de prevenção e controle que devem ser adotadas durante a assistência aos casos suspeitos ou confirmados de infecção pelo novo coronavírus (SARS-CoV-2) [internet]. Disponível em: https://www20.anvisa.gov.br/segurancadopaciente/index.php/ alertas/item/nota-tecnica 